\title{
Tariff Revenue and Tariff Caps
}

\author{
By Manuel Amador and Kyle Bagwell*
}

\section{Introduction}

Governments negotiate trade agreements in order to achieve mutual welfare gains relative to the welfares that they would enjoy in the absence of a trade agreement. Mutual gains are possible when governments preside over large countries, since an import tariff imposed by one government then generates a negative "terms-of-trade" externality for its trading partner. As a consequence of this externality, and for a wide range of political-economic government welfare functions, non-cooperative tariffs are higher than would be efficient, where efficiency is measured relative to the preferences of governments. A trade agreement can then generate mutual gains for governments by facilitating reciprocal reductions in tariffs. ${ }^{1}$

A key design feature of the GATT/WTO trade agreement is that governments negotiate "tariff bindings" - that is, tariff caps - as opposed to precise tariff levels. A tariff cap provides a government with "downward" flexibility while ensuring that it cannot achieve an opportunistic terms-of-trade gain by applying a tariff in excess of the cap. In practice, some governments excercise this flexibility and apply tariffs below negotiated tariff bindings, a phenomenon that is sometimes referred to as "binding overhang." The extent of binding overhang varies across countries, but Bacchetta and Piermartini (2011) report evidence of significant binding overhang in most of the developing world. While the distinction between applied and bound tariffs is important in GATT/WTO design and practice, relatively few theoretical analyses distinguish between applied and bound tariffs and provide interpretations of binding overhang. ${ }^{2}$

In Amador and Bagwell (2011, hereafter AB),

* Amador: Stanford University, amador@stanford.edu. Bagwell: Stanford University, kbagwell@stanford.edu. We thank Bob Staiger for helpful comments.

${ }^{1}$ See Bagwell and Staiger (1999).

${ }^{2}$ Exceptions include Amador and Bagwell (2011), Bagwell (2009), Bagwell and Staiger (2005), Beshkar, Bond and Rho (2011) and Horn, Maggi and Staiger (2010). we provide a theoretical model in which an optimal trade agreement takes the form of a tariff cap; furthermore, we show that binding overhang occurs with positive probability in an optimal trade agreement. In AB's model, the governments of two large countries negotiate a trade agreement in the presence of uncertainty as to the extent of political pressure that each will face from its import-competing industry in the future. A trade agreement specifies the set of permissible import tariffs that a government may apply. After the trade agreement is formed, each government privately observes its political pressure and applies an import tariff from the permissible set. $^{3}$ Thus, in addition to the traditional termsof-trade externality, the $\mathrm{AB}$ model features uncertainty and private information.

In AB's private-information setting, a trade agreement must be incentive compatible. This constraint places important restrictions on the feasible set of trade agreements. In particular, the fully efficient (or "first-best") tariff schedule, in which each government observes its political pressure realization and then selects the tariff that maximizes joint government welfare, is not incentive compatible. Of course, fully efficient tariffs could be implemented if governments were able to design a trade agreement in which side-payments (i.e., monetary transfers) are available as an instrument with which to transfer welfare between governments in a lump-sum fashion. ${ }^{4}$ In reality, however, sidepayments do not figure prominently in WTO rules, and explicit monetary transfers are rarely used in WTO dispute resolutions. AB thus char-

\footnotetext{
${ }^{3}$ Formally, $\mathrm{AB}$ assume that a government sets its import tariff to maximize a weighted sum of consumer surplus, tariff revenue and profit in the import-competing sector, where the welfare weight attached to profit is uncertain when the trade agreement is formed and is privately observed when the import tariff is applied. Bagwell and Staiger (2005) consider a related model and show that binding overhang occurs with positive probability when the optimal tariff cap is used. They do not, however, provide conditions under which an optimal trade agreement takes the form of a tariff cap.

${ }^{4}$ See, for example, Bagwell and Staiger (2005).
} 
acterize optimal trade agreements when transfers between governments are unavailable. ${ }^{5}$

$\mathrm{AB}$ show that the problem of designing an optimal trade agreement can be represented as a "delegation problem." ing the Lagrangian techniques of Luenberger (1969) and Amador, Werning and Angeletos (2006), AB extend the delegation literature to consider non-quadratic payoffs and give general sufficient and necessary conditions for a cap to be optimal. AB also provide sufficient and necessary conditions for a cap to be optimal when a money-burning instrument is available. In an application of the analysis, $\mathrm{AB}$ present sufficient conditions under which an optimal trade agreement takes the form of a tariff cap and generates binding overhang with positive probability (when political pressure is low).

In this paper, we characterize the design of an optimal trade agreement when a different form of private information is present. In particular, we suppose here that governments are privately informed about the value of tariff revenue. Matschke (2008) provides one microfoundation for our specification of government welfare functions. Working in a completeinformation setting, she shows that governments give extra welfare weight to tariff revenue (as compared to consumer and producer surplus) if raising revenue via wage taxation requires the use of resources for tax collection. ${ }^{7} \mathrm{We}$ suggest further that a government plausibly has some private information about the cost of raising funds in its country; hence, we assume that each government applies its tariff while in possession of some private information about its value of tariff revenue. As before, we assume that the trade agreement is designed when each government is uncertain about the precise extent to which it will later value tariff revenue.

The considerations highlighted here are po-

\footnotetext{
${ }^{5}$ To characterize the optimal trade agreement in the absence of transfers, AB employ a model that eliminates all means through which governments might achieve transfers. This is accomplished in a "partial-equilibrium" model in which export subsidies are not available and in which a numeraire good enters utility in a linear fashion and is freely traded across countries so as to achieve balanced trade. We note that the WTO prohibits the use of export subsidies.

${ }^{6}$ The delegation problem was first defined and analyzed by Holmstrom (1977). Alonso and Matouschek (2008) provide an analysis of optimal delegation when preferences are quadratic.

${ }^{7}$ See also Corden (1997, Chapter 4).
}

tentially relevant for a range of countries. We can imagine that governments often possess some private information about the economic and political costs of raising revenue through wage or income taxation. Such governments then possess private information about the marginal value of tariff revenue. These considerations may be of special relevance for some developing countries, where tax collection costs may be more uncertain.

Our first and main finding is that the problem of designing an optimal trade agreement when governments possess private information about the value of tariff revenue can be analyzed using the general findings of $\mathrm{AB}$. The problem does not immediately fit into the AB framework. The essential difficulty is that tariff revenue is not monotonic in the underlying tariff; thus, different tariffs may induce the same value for tariff revenue, with higher tariffs achieving this revenue while "burning" welfare. We present an approach for embedding this problem into the $\mathrm{AB}$ framework and using the general findings reported there for optimal delegation when a money-burning instrument is available. With this approach, it is possible to state general conditions under which an optimal trade agreement takes the form of a tariff cap. The approach presented here may facilitate other applications as well.

A second and more specific set of findings is developed in a simplified version of the trade model with linear-quadratic payoffs. For this model, we apply the general findings of $\mathrm{AB}$ and report explicit conditions for an optimal trade agreement to take the form of a tariff cap. We then assume further that a government's tariff revenue "type" is uniformly distributed and provide a closed-form representation for the optimal cap and the probability of binding overhang. The optimal tariff cap and the probability of binding overhang are higher when the upper bound of the support of the distribution is higher (indicating the possibility of a less efficient tax collection system) and when for a given mean the support of the distribution has greater width (indicating greater uncertainty). ${ }^{8}$

\footnotetext{
${ }^{8}$ Our work here complements that of Beshkar, Bond and Rho (2011). They provide theoretical and empirical support for the hypothesis that the optimal tariff cap and the probability of binding overhang are higher for smaller countries.
} 


\section{Model}

There are two countries, home and foreign, and three goods. The home country imports good $x$ from the foreign country and exports good $y$ to the foreign country. A numeraire good $n$ is also traded.

In both countries, residents share a common utility function which is additively separable across the three products, with the numeraire good entering the utility function in a linear fashion. Within any given country, the consumer demand for good $i$, where $i=x, y$, thus depends on the local price of good $i$ relative to that of the numeraire good. Each good $i$ is supplied under conditions of perfect competition, so that, within any given country, the production of good $i$, where $i=x, y$, also depends on the local price of good $i$ relative to that of the numeraire good. As is standard, the numeraire good is traded as to ensure that trade is balanced.

In this setting, market outcomes for good $x$ are independent of those for good $y$. We may thus put good $y$ to the side and focus on $\operatorname{good} x .{ }^{9} \mathrm{We}$ thus represent the utility function for consumers at home by $u\left(c^{x}\right)+c^{n}$, where $c^{x}$ and $c^{n}$ represent the respective consumption levels of good $x$ and the numeraire good. Similarly, the utility function abroad is given by $u\left(c_{\star}^{x}\right)+c_{\star}^{n}$, where the subscript $\star$ denotes the respective foreign values. The function $u$ is strictly increasing, strictly concave and thrice continuously differentiable. Let $p$ and $p_{\star}$ denote the home and foreign relative prices of good $x$ with respect to good $n$. The supply functions of good $x$ at home and abroad are given by $Q(p)$ and $Q_{\star}\left(p_{\star}\right)$ respectively. For prices that elicit strictly positive supply, the functions $Q(p)$ and $Q_{\star}\left(p_{\star}\right)$ are assumed to be strictly increasing and twice continuously differentiable. We assume that $Q(p)<Q_{\star}(p)$ for any $p$ so that good $x$ will be imported under free trade by the home country. ${ }^{10}$

Let $z$ denote the volume of international trade of good $x$. Home and foreign consumers' optimization delivers an inverse demand function for imports, $P(z)$, and an inverse supply func-

\footnotetext{
${ }^{9}$ After characterizing trade policies for the home country's import good, we may translate our findings and characterize trade policies for the foreign country's import good.

${ }^{10}$ The symmetric assumption for good $y$ ensures that good $y$ is exported under free trade by the home country.
}

tion for exports, $P_{\star}(z)$ :

$$
\begin{aligned}
u^{\prime}(Q(P(z))+z) & =P(z) \\
u^{\prime}\left(Q_{\star}\left(P_{\star}(z)\right)-z\right) & =P_{\star}(z)
\end{aligned}
$$

where $P^{\prime}(z)<0$ and $P_{*}^{\prime}(z)>0$ as implied by our assumptions.

We abstract from export policies and assume that each country has available a specific (i.e., per-unit) import tariff. If the government of the home country selects the import tariff $\tau$, then the implied import volume, $z$, is the value which satisfies $\tau=P(z)-P_{*}(z)$. Under our assumptions, a higher $\tau$ implies a lower $z$.

We restrict attention to the case where the home import tariff is non-negative and the home country imports good $x$. Thus, $z \in Z \equiv\left[0, z_{f t}\right]$, where $z_{f t}>0$ is the free trade level of imports, that is, the value such that $P\left(z_{f t}\right)=P_{\star}\left(z_{f t}\right)$.

For a given trade volume $z$, the associated producer surplus (profit) functions at home and abroad are defined as

$$
\begin{aligned}
R(z) & =\int_{\underline{p}}^{P(z)} Q(\tilde{p}) d \tilde{p}, \\
R_{\star}(z) & =\int_{\underline{p}_{*}}^{P_{\star}(z)} Q_{\star}(\tilde{p}) d \tilde{p},
\end{aligned}
$$

where $p \geq 0$ is the highest price $p$ at which $Q(p) \stackrel{\equiv}{=}$ and $p_{*} \geq 0$ is likewise the highest price $p_{*}$ at which ${ }^{*} Q_{*}\left(p_{*}\right)=0$.

We let $B(z)$ and $V(z)$ be the sum of consumer and producer surplus at home and abroad, respectively, and $T R(z)$ be the tariff revenue generated by the tariff that induces $z$. Then,

$$
\begin{aligned}
& B(z)= u(Q(P(z))+z) \\
&-P(z)(Q(P(z))+z)+R(z) \\
& V(z)=u_{\star}\left(Q_{\star}\left(P_{\star}(z)\right)-z\right) \quad-P_{\star}(z)\left(Q_{\star}\left(P_{\star}(z)\right)-z\right)+R_{\star}(z) \\
& T R(z)=\left(P(z)-P_{\star}(z)\right) z
\end{aligned}
$$

The welfare of the government of the home country is given by the sum of consumer surplus, producer surplus and tariff revenue, where we weight tariff revenue by a parameter $\gamma$ :

$$
W(z \mid \gamma)=B(z)+\gamma T R(z)
$$

As discussed by Matschke (2008), the parame- 
ter $\gamma$ thus captures the value to the home government of tariff revenue. The welfare of the foreign government is given by $V(z)$.

We further assume that $\gamma$ is uncertain at the time that the trade agreement is signed and is private information to the home government when the home tariff is applied. Let $F$ denote the continuous CDF of $\gamma$ with support on $\Gamma=[\gamma, \bar{\gamma}]$.

The optimal trade agreement is then an allocation $z():. \Gamma \rightarrow \mathbb{R}$ that maximizes ex-ante joint (government) welfare, subject to incentive compatibility of the home government:

(P)

$$
\max _{z: \Gamma \rightarrow Z} \int_{\gamma \in \Gamma}(V(z(\gamma))+W(z(\gamma) \mid \gamma)) d F(\gamma)
$$

such that

$$
W(z(\gamma) \mid \gamma) \geq W\left(z\left(\gamma^{\prime}\right) \mid \gamma\right) ; \forall \gamma, \gamma^{\prime} \in \Gamma
$$

Note that if $\gamma=1$, then joint welfare is maximized at $z_{f t} \cdot{ }^{11}$

To solve Problem $\mathrm{P}$, we consider a fictitious problem where we endow the home government with the ability to burn resources (or money). Let us define then an allocation with money burning to be a pair $(z(),. t()$.$) such that z($.$) :$ $\Gamma \rightarrow \mathbb{R}$ and $t():. \Gamma \rightarrow \mathbb{R}$, with $t(\gamma) \geq 0$ for all $\gamma \in \Gamma$. The value of $t$ represents the resources burned. The optimal trade-agreement problem with money burning is then to maximize ex-ante joint welfare, subject to incentive compatibility:

(P1)

$$
\begin{array}{r}
\max _{z: \Gamma \rightarrow Z, t: \Gamma \rightarrow \mathbb{R}} \int_{\gamma \in \Gamma}(V(z(\gamma))+W(z(\gamma) \mid \gamma) \\
-t(\gamma)) d F(\gamma)
\end{array}
$$

such that

(IC)

$$
\begin{gathered}
W(z(\gamma) \mid \gamma)-t(\gamma) \geq W\left(z\left(\gamma^{\prime}\right) \mid \gamma\right)-t\left(\gamma^{\prime}\right) \\
; \forall \gamma, \gamma^{\prime} \in \Gamma \\
t(\gamma) \geq 0 \quad ; \forall \gamma \in \Gamma
\end{gathered}
$$

The following lemma (stated without proof) shows that if we solve Problem P1 without burning resources, then we have solved Problem P:

\footnotetext{
${ }^{11}$ This follows from $V^{\prime}(z)+W^{\prime}(z \mid 1)=P(z)-P_{\star}(z)$ and $V^{\prime \prime}(z)+W^{\prime \prime}(z)=P^{\prime}(z)-P_{\star}^{\prime}(z) \leq 0$.
}

LEMMA 1: Suppose an allocation $(z(),. t()$. solves Problem P1 with $t(\gamma)=0$ for all $\gamma \in \Gamma$. Then the allocation $z($.$) solves Problem P$.

We impose the following assumption:

ASSUMPTION 1: There exists $z_{R} \in$ $\arg \max _{z \in Z} T R(z)$ such that $T R^{\prime}(z)<0$ for all $z \in\left(z_{R}, z_{f t}\right]$.

Note that $z_{R}$ must lie in the interior of $Z$ as tariff revenue is zero at the boundaries of $Z$. With this, we can restrict attention to allocations that assign to each type a trade flow that lies above the tariff-revenue maximizing level $z_{R}$ :

LEMMA 2: Let $\left(z_{0}(),. t_{0}().\right)$ be an incentive compatible allocation with money burning, that $i s$, $\left(z_{0}(),. t_{0}().\right)$ satisfies (IC). Then there always exists an allocation with money burning $\left(z_{1}(),. t_{1}().\right)$, such that $(i)\left(z_{1}(),. t_{1}().\right)$ is incentive compatible; that is, it satifies (IC); (ii) $z_{1}(\gamma) \geq z_{R}$ for all $\gamma \in \Gamma$; and (iii) $\left(z_{1}(),. t_{1}().\right)$ generates at least the same exante joint welfare.

\section{PROOF:}

Let us define $h(z)$ to be a solution to the following $T R(h(z))=T R(z)$ with the restriction that $h(z) \geq z_{R}$. Assumption 1, together with $T R(0)=T R\left(z_{f t}\right)=0$, guarantees that $h(z)$ exists for all $z \in Z$, and $h(z) \geq z$.

Let the alternative allocation be $z_{1}(\gamma)=$ $h\left(z_{0}(\gamma)\right)$ and $t_{1}(\gamma)=t_{0}(\gamma)+B\left(h\left(z_{0}(\gamma)\right)\right)-$ $\left.B\left(z_{0}(\gamma)\right)\right)$. Note that $B^{\prime}(z)=-P^{\prime}(z) z \geq 0$ for all $z \in Z$, and thus $B\left(h\left(z_{0}(\gamma)\right)\right)-B\left(z_{0}(\gamma)\right) \geq 0$ as $h\left(z_{0}(\gamma)\right) \geq z_{0}(\gamma)$. Hence, given that $t_{0}(\gamma) \geq$ 0 , it follows that $t_{1}(\gamma) \geq 0$. Next, let us check that the allocation $\left(z_{1}(),. t_{1}().\right)$ is incentive compatible. Note that:

(1)

$$
\begin{aligned}
& \gamma T R\left(z_{0}\left(\gamma^{\prime}\right)\right)+B\left(z_{0}\left(\gamma^{\prime}\right)\right)-t_{0}\left(\gamma^{\prime}\right) \\
& =\gamma T R\left(h\left(z_{0}\left(\gamma^{\prime}\right)\right)\right)+B\left(h\left(z_{0}\left(\gamma^{\prime}\right)\right)\right) \\
& \quad-t_{0}\left(\gamma^{\prime}\right)-\left(B\left(h\left(z_{0}\left(\gamma^{\prime}\right)\right)\right)-B\left(z_{0}\left(\gamma^{\prime}\right)\right)\right) \\
& =\gamma T R\left(z_{1}\left(\gamma^{\prime}\right)\right)+B\left(z_{1}\left(\gamma^{\prime}\right)\right)-t_{1}\left(\gamma^{\prime}\right)
\end{aligned}
$$

Thus the new allocation delivers the same utility to the home government as the original allocation, as a function of its true type $\gamma$ and its announcement $\gamma^{\prime}$. Hence, if the original allocation was incentive compatible, so is the 
new one. Parts (i) and (ii) are satisfied. Finally, note that $V^{\prime}(z)=P_{\star}^{\prime}(z) z \geq 0$, and hence $V\left(z_{0}(\gamma)\right) \leq V\left(z_{1}(\gamma)\right)$. Part (iii) then follows as $W\left(z_{0}(\gamma) \mid \gamma\right)-t_{0}(\gamma)=W\left(z_{1}(\gamma) \mid \gamma\right)-t_{1}(\gamma)$ by equation (1). QED.

Lemma 2 guarantees that, when solving Problem $\mathrm{P} 1$, we can restrict attention to allocations with $z(\gamma) \in\left[z_{R}, z_{f t}\right]$. Assumption 1 implies that the function $T R$ is invertible in $\left[z_{R}, z_{f t}\right]$; that is, there exists a function $T R^{-1}:\left[0, T R\left(z_{R}\right)\right] \rightarrow\left[z_{R}, z_{f t}\right]$ such that $z=T R^{-1}(T R(z))$. Let $\pi \in \Pi=\left[0, T R\left(z_{R}\right)\right]$ denote a level of tariff revenue. Let us define the following functions: $b(\pi)=B\left(T R^{-1}(\pi)\right)$ and $v(\pi)=V\left(T R^{-1}(\pi)\right)$. Then, consider the following problem:

$$
\begin{array}{r}
\max _{\pi: \Gamma \rightarrow \Pi, t: \Gamma \rightarrow \mathbb{R}} \int_{\Gamma}(v(\pi(\gamma))+\gamma \pi(\gamma)+b(\pi(\gamma)) \\
-t(\gamma)) d F(\gamma)
\end{array}
$$

subject to:

$$
\begin{aligned}
\gamma \pi(\gamma)+b(\pi(\gamma))-t(\gamma) & \geq \gamma \pi\left(\gamma^{\prime}\right)+b\left(\pi\left(\gamma^{\prime}\right)\right) \\
& -t\left(\gamma^{\prime}\right) \quad ; \forall \gamma, \gamma^{\prime} \in \Gamma \\
t(\gamma) & \geq 0 \quad ; \forall \gamma \in \Gamma
\end{aligned}
$$

Solving Problem P1 is equivalent to solving Problem P2, and it follows from Lemma 1 that:

PROPOSITION 1: Suppose $(\pi(),. t()$.$) solves$ Problem P2 with $t(\gamma)=0 \forall \gamma$. Then, the allocation $z($.$) , such that z(\gamma)=T R^{-1}(\pi(\gamma)) \forall \gamma$, solves Problem $P$.

Importantly, Problem P2 is a special case of the framework developed by AB. Using this framework, AB obtain sufficient (and necessary) conditions for a tariff cap to be an optimal agreement in the presence of money burning. ${ }^{12}$ Rather than reporting those conditions here, we instead proceed to apply AB's results to the commonlyused linear-quadratic case.

\footnotetext{
${ }^{12}$ In AB's trade application, $\pi(\gamma)$ is a profit allocation, which uniquely defines a trade volume allocation. By contrast, here $\pi(\gamma)$ is a tariff revenue allocation, which under Proposition 1 implies a trade volume allocation. In both settings, the tariff allocation is uniquely defined by the trade volume allocation.
}

\section{The Linear-Quadratic Case}

Let preferences and technology be as follows: $Q(p)=p / 2, Q_{\star}(p)=p$, and $u(c)=c-$ $c^{2} / 2$. The respective values of $B, V$ and $T R$ are $B(z)=\frac{1}{6}\left(1+2 z^{2}\right), V(z)=\frac{1}{4}\left(1+z^{2}\right)$ and $T R(z)=\frac{1}{6} z(1-7 z)$

The free trade level of trade is $z_{f t}=1 / 7$, and the trade level that maximizes tariff revenue is $z_{R}=1 / 14$, which delivers a tariff revenue of $1 / 168$. Since $T R$ is a quadratic and strictly concave function, it satisfies Assumption 1. Hence, we can restrict attention to $z \in[1 / 14,1 / 7]$. We can then obtain $b(\pi)$ and $v(\pi)$, which are given by (up to some constant terms):

$$
\begin{aligned}
& b(\pi)=\frac{1}{294}(\sqrt{1-168 \pi}-84 \pi), \text { and } \\
& v(\pi)=\frac{1}{392}(\sqrt{1-168 \pi}-84 \pi)
\end{aligned}
$$

with $\pi \in \Pi \equiv[0,1 / 168]$. Note that $b^{\prime \prime}(\pi)<0$ and $v^{\prime \prime}(\pi)<0$. Note also that $v^{\prime}(\pi)<0$.

Let the flexible allocation be $\pi_{f}(\gamma)=$ $\arg \max _{\pi}(\gamma \pi+b(\pi))$, that is, the level of tariff revenue that the home government unilaterally chooses in the absence of an agreement. We impose that $\gamma>4 / 7$, so that the flexible allocation is always interior, and given by $\pi_{f}(\gamma)=$ $\frac{\gamma(7 \gamma-4)}{24(7 \gamma-2)^{2}}$. Note that $\pi_{f}^{\prime}(\gamma)=\frac{1}{3(7 \gamma-2)^{3}}>0$ and that $\lim _{\gamma \rightarrow \infty} \pi_{f}(\gamma)=1 / 168$.

A cap allocation is defined as one that assigns to all types below some cutoff $\gamma_{h}$ their flexible allocation, while forcing all types above $\gamma_{h}$ to pool at the flexible allocation of type $\gamma_{h}$. The optimal cap allocation within the set of caps can then be found by solving the following problem:

$$
\begin{gathered}
\gamma_{h}=\arg \max _{c} \int_{\underline{\gamma}}^{c}\left(v\left(\pi_{f}(\gamma)\right)+b\left(\pi_{f}(\gamma)\right)\right. \\
\left.+\gamma \pi_{f}(\gamma)\right) d F(\gamma) \\
+(1-F(c)) \times \\
\left(v\left(\pi_{f}(c)\right)+b\left(\pi_{f}(c)\right)+\pi_{f}(c) \mathbb{E}\left[\gamma \mid \gamma>\gamma_{h}\right] .\right)
\end{gathered}
$$

The associated first order condition is

$$
\mathbb{E}\left[\gamma \mid \gamma \geq \gamma_{h}\right]=\frac{7}{4} \gamma_{h},
$$

which has an interior solution if $\mathbb{E}[\gamma]>\frac{7}{4} \underline{\gamma}$.

We can now state the following proposition, 
whose proof is a direct application of results in $\mathrm{AB}:{ }^{13}$

PROPOSITION 2: Suppose $\mathbb{E}[\gamma]>\frac{7}{4} \gamma$ so that $\gamma_{h} \in(\gamma, \bar{\gamma})$ exists such that (2) is satisfied. If further $(i) 7 f(\gamma)+3 \gamma f^{\prime}(\gamma) \geq 0$ for all $\gamma \in\left[\gamma, \gamma_{h}\right]$, and (ii) $3 \gamma_{h} / 4 \geq E[\tilde{\gamma} \mid \tilde{\gamma} \geq \gamma]-\gamma$ for all $\gamma \in\left[\gamma_{h}, \bar{\gamma}\right]$, then the optimal trade agreement takes the form of a cap allocation with cutoff $\gamma_{h}$.

Thus, under the conditions stated in Proposition 2, an optimal trade agreement can be implemented with a tariff cap, where types below $\gamma_{h}$ apply (flexible) tariffs that lie below the cap.

We now focus on the case of a uniform distribution. It is then direct to confirm that parts (i) and (ii) of the Proposition 2 are satisfied. Assuming $2 \bar{\gamma} / 5>\gamma$, an interior cap type exists: $\gamma_{h}=2 \bar{\gamma} / 5$. The associated tariff cap $\tau_{c}$ is:

$$
\tau_{c}=\frac{1}{12}\left(1+\frac{5}{5-7 \bar{\gamma}}\right)
$$

The tariff cap level, $\tau_{c}$, and the cap type, $\gamma_{h}$, are increasing in $\bar{\gamma}$. The probability of binding overhang is the probability that the cap is not binding ex-post, that is, $F\left(\gamma_{h}\right)$. Using $\gamma_{h}=$ $2 \bar{\gamma} / 5$, it follows that $F\left(\gamma_{h}\right)=\frac{2 \bar{\gamma}-5 \underline{\gamma}}{5(\bar{\gamma}-\underline{\gamma})}>0$. The probability of binding overhang is increasing in $\bar{\gamma}$ and is thus greater when the maximal possible value of tariff revenue is higher.

The uniform distribution may also be described by its mean, $\mu \equiv(\gamma+\bar{\gamma}) / 2$, and support width, $\sigma \equiv \bar{\gamma}-\gamma$. The interior cap type is then $\gamma_{h}=(2 \mu+\sigma) / 5$ and the probability of binding overhang is $F\left(\gamma_{h}\right)=\frac{7}{10}-\frac{3 \mu}{5 \sigma}$. For a given mean, an increase in uncertainty as captured by greater support width results in a higher tariff cap and a greater probability of binding overhang. We hope to consider comparative statics for more general distributions in future work.

\section{REFERENCES}

Alonso, Ricardo, and Niko Matouschek. 2008. "Optimal Delegation." The Review of Economic Studies, 75(1): pp. 259-293.

\footnotetext{
${ }^{13}$ In particular we can apply Proposition 2 of AB. Condition (c1) of Proposition 2 in $\mathrm{AB}$ corresponds to part (i). Condition (c2) corresponds to part (ii) plus the existence of $\gamma_{h}$. And condition (c3') is satisfied as $v^{\prime}\left(\pi_{f}(\underline{\gamma})\right)<0$.
}

Amador, Manuel, and Kyle Bagwell. 2011. "The Theory of Optimal Delegation with An Application to Tariff Caps." Stanford University Working paper.

Amador, Manuel, Iván Werning, and GeorgeMarios Angeletos. 2006. "Commitment vs. Flexibility.” Econometrica, 74(2).

Bacchetta, Marc, and Roberta Piermartini. 2011. "The Value of Bindings." World Trade Organization Staff Working Paper ERSD2011-13.

Bagwell, Kyle. 2009. "Self-Enforcing Trade Agreements and Private Information." NBER Working Papers 14812.

Bagwell, Kyle, and Robert W. Staiger. 1999. "An Economic Theory of GATT." American Economic Review, 89(1): 215-248.

Bagwell, Kyle, and Robert W. Staiger. 2005. "Enforcement, Private Political Pressure, and the General Agreement on Tariffs and Trade/World Trade Organization Escape Clause." Journal of Legal Studies, 34: 471513.

Beshkar, Mostafa, Eric Bond, and Youngwoo Rho. 2011. "Tariff Binding and Overhang: Theory and Evidence." Working paper.

Corden, W. Max. 1997. Trade Policy and Economic Welfare, Second Edition. Clarendon Press: Oxford.

Holmstrom, Bengt. 1977. "On Incentives and Control in Organizations." PhD diss. Stanford University.

Horn, Henrik, Giovanni Maggi, and Robert W. Staiger. 2010. "Trade Agreements as Endogenously Incomplete Contracts." American Economic Review, 100(1): 394419.

Luenberger, David .G. 1969. Optimization by vector space methods. Series in decision and control, Wiley.

Matschke, Xenia. 2008. "Costly revenueraising and the case for favoring importcompeting industries." Journal of International Economics, 74(1): 143-157. 